\title{
Correlation of functional mobility with handgrip strength, functional capacity for instrumental activities of daily living, fear of falling and number of falls in community-dwelling elderly
}

Correlação entre mobilidade funcional e força de preensão palmar,
capacidade funcional para atividades instrumentais de vida diária,
medo de cair e número de quedas em idosos residentes na comunidade

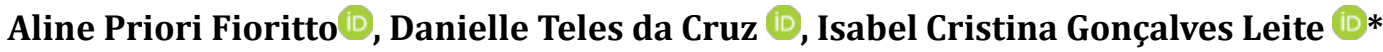

Universidade Federal de Juiz de Fora (UFJF), Juiz de Fora, MG, Brazil

Abstract

Introduction: Functional mobility is essential for quality life and its worsening is the first sign of functional decline in the elderly. Objective: To assess the correlation of functional mobility with handgrip strength (HGS), functional capacity for IADL (FC-IADL) and fear of falling and number of falls in community-dwelling elderly. Method: A cross-sectional study was conducted with 303 community-dwelling elderly of both sexes, in Juiz de Fora (MG, Brazil). Functional mobility (TUG), HGS (dynamometer, JAMAR), FC-IADL (Lawton and Brody Scale), fear of falling (FES-I-Brazil) and number of falls were assessed. The data were analyzed using Pearson's correlation test, and significance was established at $\leq 5 \%$. Results: The elderly studied consisted of $61.7 \%$ females, were $73.5 \pm 7.8$ years old and had little schooling ( $4.3 \pm 3.5$ years). Functional mobility showed a moderate correlation with HGS ( $r=-0.383$ and $r=-0.322$; women and men respectively) and FCIADL ( $\mathrm{r}=-0.568$ and $\mathrm{r}=-0.583$ ) in both sexes and fear of falling $(\mathrm{r}=0.511)$ in females, a weak correlation with fear of falling in males $(r=0.243)$ and number of falls in both sexes $(r=0.101$ and $r=0.195)$. Conclusion:

*APF: MS, e-mail: aline.priori.fioritto@gmail.com

DTC: PhD, e-mail: danitcruz@yahoo.com.br

ICGL: PhD, e-mail: isabel.leite@ufjf.edu.br 
Functional mobility showed a moderate correlation with HGS and FC-IADL in both sexes and fear of falling in females. It showed a weak correlation with fear of falling in males and number of falls in both sexes. The overestimated self-efficacy to prevent falls in men and the protective role of fear of falling in individuals with functional mobility limitations may explain these findings.

Keywords: Aged. Health of the Elderly. Mobility Limitation. Accidental Falls. Cross-Sectional Studies.

\section{Resumo}

Introdução: Mobilidade funcional é fundamental para uma vida com qualidade e a sua piora é o primeiro sinal de declínio funcional em idosos. Objetivo: Avaliar a correlação entre mobilidade funcional, força de preensão palmar (FPP), capacidade funcional para atividades instrumentais de vida diária (CF-AIVD), medo de cair e número de quedas em idosos comunitários. Método: Estudo transversal, com 303 idosos comunitários de ambos os sexos, em de Juiz de Fora (MG). Avaliou-se mobilidade funcional (TUG), FPP (dinamômetro JAMAR), CF-AIVD (Escala de Lawton e Brody), medo de cair (FES-I-Brasil) e número de quedas. Foi utilizado o Teste de Correlação de Pearson e adotada significância $\leq 5 \%$. Resultados: 61,7\% do sexo feminino, idade de 73,5 \pm 7,8 anos e baixa escolaridade $(4,3 \pm 3,5)$. Mobilidade funcional apresentou correlação moderada com FPP $(r=$ $-0,383$ e $r=-0,322$; mulheres e homens, respectivamente) e CF-AIVD ( $r=-0,568 ; r=-0,583)$ em ambos os sexos e medo de cair $(r=0,511)$ em mulheres, correlação fraca com medo de cair em homens $(r=0,243)$ e número de quedas ( $r=0,101 ; r=0,195)$ em ambos os sexos. Conclusão: Mobilidade funcional apresentou correlação moderada com FPP e CF-AIVD em ambos os sexos e medo de cair em mulheres e correlação fraca com medo de cair em homens e número de quedas em ambos os sexos. A autoeficácia para evitar quedas superestimada nos homens e o papel protetor do medo de cair, principalmente nas mulheres, podem justificar esses achados.

Palavras-chave: Idoso. Saúde do Idoso. Limitação da Mobilidade. Acidentes por Quedas. Estudos Transversais.

\section{Introduction}

Functional mobility or the ability to move around independently is essential for quality of life, and often, when it worsens, it is the first sign of functional decline in the elderly, with consequent increase in the occurrence of falls in this population [1-6]. Approximately $55 \%$ of falls in an elderly community are related to changes in mobility [3, 7-9].

There are many instruments that assess the different aspects of mobility [5, 10-14]. Accordingly, Timed Up and Go (TUG) [14] is an instrument that, when compared with others for assessing functional mobility, has some advantages in being being safe, fast and easy to apply to community-dwelling elderly, in addition to being low cost and available in the public domain [11-13]. TUG evaluates performance in motor tasks essential for an independent life such as controlling the descent to a sitting position and the rise to an upright position, which are important, for example, in the following activities: using the bed, a chair and toilet; walking a short distance to answer the phone in time and crossing the street; and changing the direction of a walk [10,13-15].

In community-dwelling elderly, TUG performance is influenced by muscle strength, balance, hearing, vision, pain in the lower limbs, cognitive function, reported morbidities, sex and age [1, 3-5, 7]. The longer time needed in the test was also related to low handgrip strength (HGS), limitations in Instrumental Activities of Daily Living (IADL), low gait speed, worse scores on the Barthel index, Tinetti test and Berg Balance Scale and the fear of falling $[3,6,7,14,16-18]$.

Given the above, the objective of our study was to determine the correlation of functional mobility assessed by TUG performance with HGS, functional capacity to perform IADL (FC-IADL), fear of falling and the number of falls in community-dwelling elderly people of both sexes. 
Method

\section{Ethical aspects of research}

Regulatory Guidelines and Norms for Research Involving Humans were obeyed, in accordance with Resolution 466/2012 of the National Health Council of Brazil. The study was approved by the Institutional Ethics Committee (protocol No. 771/916) and all subjects provided written informed consent prior to participation. The Strengthening the Reporting of Observational Studies in Epidemiology [19] guidelines were followed in reporting this study.

\section{Study Design, Setting and Sample Size}

This study was part of the broader research project Health Survey of the Elderly Population of Juiz de Fora (Inquérito em Saúde da População Idosa de Juiz de Fora - ISPI-JF), conducted through two phases of multidimensional household surveys that were population-based (2010/2011 and 2014/2015) [20]. This was a cross-sectional study of the second wave of data collection (2014/2015), which included a sample of elderly people 60 years and older, of both sexes, living in the community, in Juiz de Fora, Minas Gerais.

To define the sample calculation at the beginning of the follow-up in 2010, the national prevalence of elderly people who suffered a fall (30\%) [21] was considered, since this was the main objective. We considered a maximum desired error of 5\%, 95\% confidence level, correction for finite populations, effect of the sampling design equal to 1.5 (considering possible effects of stratification and clustering, according to the selection procedure adopted) and possible losses due to refusal (30\%).

Participants were selected by stratified and multi-stage clustered random sampling. The primary sampling units were the census sectors. For the sorting, the sectors were grouped into strata defined according to the different types of health care to which the sector's population was assigned, subdivided into primary care (Family Health Strategy or traditional), secondary care or uncovered area. These were selected with probabilities proportional to their size (resident population according to data from the 2000 demographic census) independently in each stratum.

For the second phase of the ISPI-JF, we estimated the sample size from data in previous work and from the results of the 2010 IBGE census related to the population of the study area, at the level of census tract breakdown. There were changes in the population and in the distribution of these tracts, which required the resizing of the representative probabilistic sample based on stratification and clustering. To make up for the loss of panel members, we used the oversampling method [22], allowing the initial sampling to be respected, as long as the initial population was known and statistical treatment and weight assignment were different between the groups that made up each situation of the panel member lost. We selected age, sex and education level as the variables to indicate the entry of new subjects. A total of 423 elderly people were eligible for the study. Those who showed behavior on the Mini Mental State Examination (MMSE) suggestive of cognitive decline and who were not accompanied by caregivers were excluded $(n=23)$. The total sample of the second phase of ISPI-JF was 400 elderly individuals.

Functional mobility was assessed by TUG. The Edmonton Fragility Scale (EFE) [23] was used in ISPI-JF, in which the functional performance domain is assessed by TUG. The cognitive domain is the first domain for the evaluation of EFE and determines which elderly people will be evaluated in the other domains, including functional performance. The elderly who showed results suggestive of cognitive decline and who had no other respondent were excluded. Of the 400 elderly individuals who composed the ISPI-JF sample, 61 were excluded from the present study because they did not meet the criteria proposed in the EFE, leaving 339 individuals.

\section{Participants}

A total of 339 elderly people of both sexes, aged 60 years or older, participants of the second phase of ISPI-JF, were selected for the study. Elderly who were bedridden, had health conditions that made them need mobility assistance or who refused to perform TUG were precluded from the sample.

\section{Descriptive variables}

Sociodemographic variables (sex, age, years of schooling, skin color and socioeconomic status), health status (long-term use of prescription drugs, reported comorbidities, self-perceived health), history of falls, FC-IADL and fear of falling were included. 
Main variables and assessment tools

Functional mobility was assessed through TUG performance [14], widely used in research and clinical practice [11-14]. It has high test-retest reliability with an intraclass correlation coefficient of 0.96 [11-14]. According to Podsiadlo and Richardson [14], the greater the time spent by the elderly to complete the test, the worse their functional mobility is. In the same study, those elderly people who completed the test in 10 seconds or less were considered to have no functional mobility changes, whereas those who completed TUG in 30 seconds or more had substantial functional mobility limitations.

For the test, the individual was given the following command: "I would like you to sit in this chair with your back and arms supported. When I say "GO," please stand and walk to the mark on the floor (three meters away), go back to the chair and sit down again". A Technos digital stopwatch, model YP2151, was used and the time in seconds was recorded.

HGS was measured with the Jamar hydraulic handheld dynamometer (Hydraulic Hand Dynamometer SH5001) and in accordance with the recommendations of the American Society of Hand Therapists [24]. During the measurement procedures, the participants were in a sitting position, holding the dynamometer with the dominant hand, and with the elbow at 90 degrees of flexion, forearm in neutral position and wrist positioned at between 0 to 30 degrees of extension. The elderly persons were encouraged to exert maximum strength for six seconds, and a one-minute rest interval was given between attempts. The average measurement after three rounds was determined in kilogram-force (kgf).

FC-IADL investigation was conducted using the Lawton and Brody Scale (LBS) [25]. Nine IADLs are investigated: using the phone, shopping, taking care of money, preparing their own meals, tidying up the house, doing housework, washing clothes, taking medicines and going to distant places using some form of transportation. For each IADL questioned, three possibilities are proposed: perform without help (3 points), perform with partial help ( 2 points), and fail to perform (1 point). The score ranges from 9 (total dependence) to 27 (total independence). The cut-off point $>18$ was adopted for independent elderly persons in the descriptive analysis of the sample [20].
Falls Efficacy Scale-International-Brazil (FES-IBrazil) was used to evaluate fear of falling [26]. This scale consists of 16 different daily activities, ranging from simpler activities to those that require a greater degree of independence. There are four possible responses, with respective scores of one to four (not at all concerned, a little concerned, very concerned and extremely concerned). The elderly are asked about their concern with the possibility of falling when performing these activities. If the individual does not do the activity, he is instructed to respond by imagining how he would feel when performing it. The score ranges from 16 (not concerned) to 64 (extremely concerned). A cut-off point of 23 was adopted to characterize the fear of falling [27] and also corresponded to the median score of the sample of individuals who performed the FES-I-Brazil at ISPI-JF ( $\mathrm{N}=255)$.

The number of falls was investigated by asking subjects the question: "Did you fall anytime during the last year? If yes, how many times?" The history of falls (yes or no) and the number of falls were recorded.

\section{Statistical analysis}

The results were submitted to descriptive analysis using the mean and standard deviation (SD) for the quantitative variables, and absolute and relative frequencies for the categorical variables. Normality of the data was evaluated using the KolmogorovSminorv test. The Student-t test and chi-square test were performed to compare, respectively, the mean values and proportions between the sexes. The correlation of HGS, FC-IADL, fear of falling and number of falls with functional mobility was determined using Pearson's correlation test, and the following strength classification was attributed: strong ( $r>0.7$ ), moderate ( $r$ between 0.3 and 0.7 ) and weak $(r<0.3)$ [28]. The behavior of the variables was observed in a general way, separately, between sexes and also in the subgroup of elderly people 80 or older. Data analysis was conducted using the Statistical Package for the Social Sciences, version 15.0 , and the significance level was set at $\alpha \leq 5 \%$. 


\section{Results}

Of the potential study sample of 339 subjects, 36 were excluded, so the final sample consisted of 303 elderly persons (Figure 1). The participants' characteristics are shown in Table 1. Most participants were female (61.7\%), aged $73.5 \pm 7.8$ (mean \pm SD) years, with age ranging from 60 to 101 years and had only few years of schooling ( 4.3 \pm 3.5 ). The mean number of falling episodes in the last 12 months was $1.6 \pm 1.1$, and there was no difference between sexes. The mean performance time in TUG was $13.3 \pm 5.9$ seconds, with better performance for men than women $(12.1 \pm 5.9$ versus $14.0 \pm 5.7 ; \mathrm{p}=0.006)$. HGS (32.2 \pm 8.4 versus $20.6 \pm 5.1 \mathrm{kgF} ; \mathrm{p}<0.001)$, LBS (25.4 \pm 2.9 versus $23.5 \pm 4.5 ; \mathrm{p}<0.001$ ) and FES-I-Brazil $(22.2 \pm 5.5$ versus $24.9 \pm 6.8 ; p=0.002)$ also showed significant differences between sexes (Table 1 ).

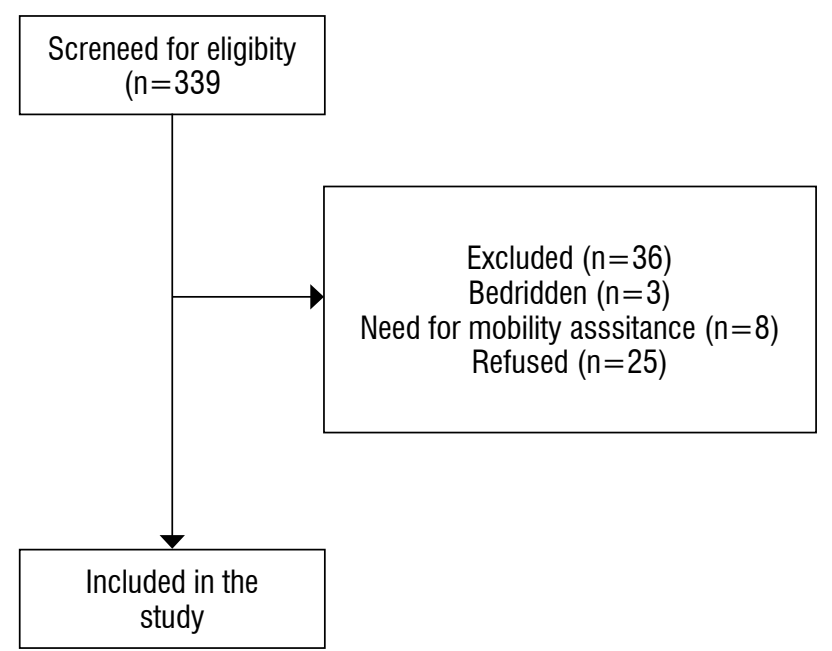

Figure 1 - Participant flow diagram.

Table 1 - Participants' characteristics

\begin{tabular}{|c|c|c|c|c|}
\hline Variables & Total $n=303$ & Female $n=187$ & Male $n=116$ & $p$ value \\
\hline $\begin{array}{l}\text { Sex, \% } \\
\text { Age, mean } \pm \text { SD }\end{array}$ & $\begin{array}{c}100.0 \\
73.5 \pm 7.8\end{array}$ & $\begin{array}{c}61.7 \\
73.2 \pm 8.1\end{array}$ & $\begin{array}{c}38.3 \\
73.8 \pm 7.3\end{array}$ & $\begin{array}{l}<0.001^{*} \\
0.522\end{array}$ \\
\hline $\begin{array}{l}\text { Formal education years, } \\
\text { mean } \pm S D\end{array}$ & $4.3 \pm 3.5$ & $3.8 \pm 2.9$ & $5.1 \pm 3.8$ & $0.001^{*}$ \\
\hline $\begin{array}{l}\text { Skin color, \% } \\
\text { White } \\
\text { Non-white }\end{array}$ & $\begin{array}{l}52.5 \\
475\end{array}$ & $\begin{array}{l}46.5 \\
535\end{array}$ & $\begin{array}{l}62.1 \\
37.9\end{array}$ & $0.013^{\star}$ \\
\hline $\begin{array}{l}\text { Non-white } \\
\text { Socioeconomic status, \% }\end{array}$ & 47.5 & 53.5 & 37.9 & 0.168 \\
\hline $\begin{array}{l}\text { A-B } \\
C \\
D-E\end{array}$ & $\begin{array}{l}32.0 \\
60.1 \\
7.9\end{array}$ & $\begin{array}{l}31.6 \\
58.3 \\
10.2\end{array}$ & $\begin{array}{c}32.8 \\
62.9 \\
4.3\end{array}$ & \\
\hline $\begin{array}{l}\text { Long-term use of } \\
\text { medications, mean } \pm \\
\text { SD years }\end{array}$ & $4.3 \pm 2.7$ & $4.2 \pm 2.8$ & $4.2 \pm 2.5$ & 0.822 \\
\hline Reported comorbidities, \% & & & & $0.023^{*}$ \\
\hline $\begin{array}{l}\text { Yes } \\
\text { No } \\
\text { Solf_parcoiver halth o }\end{array}$ & $\begin{array}{l}89.1 \\
10.9\end{array}$ & $\begin{array}{l}92.5 \\
7.5\end{array}$ & $\begin{array}{l}83.6 \\
16.4\end{array}$ & \\
\hline $\begin{array}{l}\text { Self-perceived health, \% } \\
\text { Negative }\end{array}$ & 39.7 & 41.6 & 36.6 & \\
\hline Positive & 60.3 & 58.4 & 63.4 & \\
\hline $\begin{array}{l}\text { History of falls, \% } \\
\text { Yes } \\
\text { No }\end{array}$ & $\begin{array}{l}33.7 \\
66.3\end{array}$ & $\begin{array}{l}35.3 \\
64.7\end{array}$ & $\begin{array}{l}31.0 \\
69.0\end{array}$ & 0.355 \\
\hline $\begin{array}{l}\text { Number of falls, } \\
\text { mean } \pm \mathrm{SD} \\
\text { Fear of falling, \% }\end{array}$ & $1.6 \pm 1.1$ & $1.6 \pm 0.9$ & $1.6 \pm 1.4$ & $\begin{array}{l}0.779 \\
<0001 *\end{array}$ \\
\hline $\begin{array}{l}\text { Yes } \\
\text { No }\end{array}$ & $\begin{array}{l}40.1 \\
59.9\end{array}$ & $\begin{array}{l}47.0 \\
53.0\end{array}$ & $\begin{array}{l}29.0 \\
71.0\end{array}$ & \\
\hline $\begin{array}{l}\text { FES-I-Brazil, mean } \pm \text { SD } \\
\text { FC-IADL, \% }\end{array}$ & $23.8 \pm 6.6$ & $24.9 \pm 6.8$ & $22.2 \pm 5.5$ & $\begin{array}{l}0.002^{*} \\
0.001^{*}\end{array}$ \\
\hline $\begin{array}{l}\text { Dependent } \\
\text { Independent }\end{array}$ & $\begin{array}{l}10.2 \\
89.9\end{array}$ & $\begin{array}{l}15.0 \\
85.0\end{array}$ & $\begin{array}{l}2.6 \\
97.4\end{array}$ & \\
\hline $\begin{array}{l}\text { LBS, mean } \pm \text { SD } \\
\text { HGS, mean } \pm S D\end{array}$ & $\begin{array}{l}24.3 \pm 4.0 \\
25.1 \pm 8.7\end{array}$ & $\begin{array}{l}23.5 \pm 4.5 \\
20.6 \pm 5.1\end{array}$ & $\begin{array}{l}25.4 \pm 2.9 \\
32.2 \pm 8.4\end{array}$ & $\begin{array}{l}<0.001^{*} \\
<0.001^{*}\end{array}$ \\
\hline $\begin{array}{l}\text { TUG performance, } \\
\text { mean } \pm \text { SD }\end{array}$ & $13.3 \pm 5.9$ & $14.0 \pm 5.7$ & $12.1 \pm 5.9$ & $0.006^{*}$ \\
\hline
\end{tabular}

Note: Results are reported as mean and standard deviation (SD), absolute (n) and relative (\%) values. Abbreviations: FES-I-Brazil = Falls Efficacy Scale-International-Brazil; FC-IADL = functional capacity to perform the instrumental activities of daily living; LBS = Lawton and Brody scale; HGS $=$ handgrip strength; TUG $=$ timed up and go. ${ }^{*}$ Statistically significant differences. 

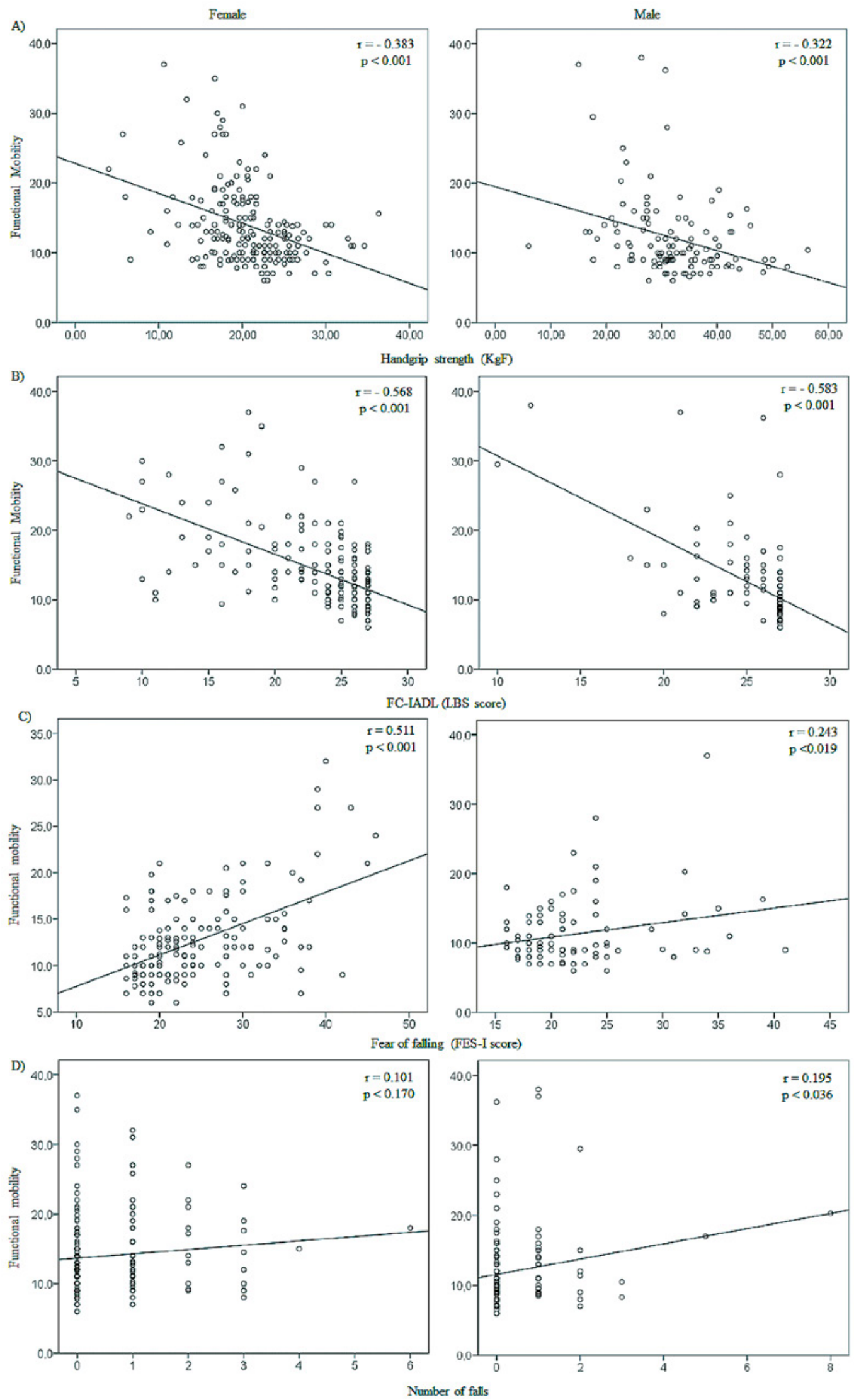

Figure 2 - Correlation between functional mobility and HGS (A), FC-IADL (B), fear of falling (C) and number of falls (D) according to sex. 
Functional mobility showed a moderate correlation with HGS ( $\mathrm{r}=-0.383$ and $\mathrm{r}=-0.322)$ and with FC-IADL $(r=-0.568$ and $r=-0.583)$ in women and men, respectively; and with fear of falling in women $(r=0.511)$. It showed a weak correlation with fear of falling in men $(r=0.243)$ and with number of falls $(r=0.101$ and $r=0.195)$ in both sexes (Figure 2). In the general analysis, functional mobility showed a moderate correlation with HGS $(\mathrm{r}=-0.356 ; \mathrm{p}<0.001)$, FC-IADL $(\mathrm{r}=-0.573 ; \mathrm{p}<$ $0.001)$ and fear of falling $(r=0.475 ; p<0.001)$ and a weak correlation with number of falls $(r=0.046$; $\mathrm{p}=0.649)$.

When analyzing the behavior of the correlations in the stratum of elderly people aged 80 years or older ( $\mathrm{n}=72)$, a moderate correlation between functional mobility and HGS was observed in the general analysis ( $r=-0.428 ; p<0.001)$ and a weak correlation in women and men $(r=-0.296 ; p=0.067$ and $\mathrm{r}=-0.210 ; \mathrm{p}=0.293$, respectively). A moderate correlation with FC-IADL was seen in the general analysis $(\mathrm{r}=-0.422 ; \mathrm{p}<0.001)$ and in men $(\mathrm{r}$ $=-0.462 ; p=0.015)$ and a weak correlation in women $(\mathrm{r}=-0.273 ; \mathrm{p}=0.080)$. A moderate correlation with fear of falling was found in the general analysis ( $\mathrm{r}$ $=0.395 ; \mathrm{p}=0.10)$ and in women $(\mathrm{r}=-0.614 ; \mathrm{p}=$ $0.003)$ and a weak correlation in men $(r=-0.026 ; p=$ 0.912 ). A weak correlation with number of falls was seen in the general analysis $(r=0.133 ; p=0.452)$ and in women $(\mathrm{r}=-0.062 ; \mathrm{p}=0.790)$ and a moderate correlation in men $(r=0.392 ; p=0.185)$.

\section{Discussion}

The present study suggests that better functional mobility, represented by performance in TUG, is related to greater HGS, higher level of independence in IADL, better self-efficacy in avoiding falls and a tendency toward fewer episodes of falls in one year. Additionally, with the exception of number of falls, there was a statistically significant difference in the means and proportions between the sexes. When analyzing the subgroup of long-lived elderly people, it was also possible to observe the influence of age for underscoring the relationships found. Such findings suggest that, although the behavior of the relationships is similar, their degree may vary and, therefore, the particularities inherent to gender and age must both be taken into account during data analysis and in the decision-making that will guide clinical practice.

There is no consensus in the literature regarding the cut-off point used for the classification of functional mobility in community-dwelling elderly, which will depend on several factors, including the characteristics of the population studied, the assessment instrument used, the application protocol for the instrument used, and other methodological attributes as well $[4,6,7,13$ 15]. In the present study, mean performance in TUG was significantly better in men compared to women (12.1 \pm 5.9 versus $14 \pm 5.7$ seconds; $p=0.006)$. The methodological quality of this research provides a reference for studies with similar populations.

Functional mobility is an indicator identified as essential for a quality life [2-5]. A recent study found TUG performance to be an important predictor of allcause mortality $(\mathrm{HR}=1.79 ; 95 \% \mathrm{CI}=1.33-2.42 ; \mathrm{p}<$ 0.001 ) in a sample of 1005 community-dwelling elderly followed for 11.8 years old [3]. In that same study, TUG performance was better in males than females, but the association with mortality risk was equally robust between the sexes. For each additional second in TUG, there was an $8 \%$ increase in mortality risk.

The reason why TUG can be predictive of mortality in community-dwelling elderly is that worsening of functional mobility is one of the first signs of functional decline, and therefore, functional mobility may reflect the burden of comorbidities affecting the systems involved in its maintenance $[2-4,8,9]$. It is worth emphasizing the importance of multiple interactions between different body systems (nervous, vestibular, proprioceptive, cardiopulmonary and musculoskeletal systems) responsible for maintaining functional mobility [2-4, 9]. Therefore, intervention strategies with a comprehensive approach that considers the different aspects involved with the decline in functional mobility are indicated, since they provide better outcomes for the health of the elderly population $[3,4,6]$.

HGS is a simple and objective measure that has been associated with a series of important clinical health outcomes [17, 29-33]. Granic et al. [31] followed a cohort of 845 community-dwelling elderly for 9.6 years to investigate the association between the rate of change in HGS and all-cause mortality. Elderly people who suffered a decline in HGS during the study had a $31 \%$ higher risk of mortality $(\mathrm{HR}=1.31 ; 95 \% \mathrm{CI}=1.18$ 1.45; $\mathrm{p}<0.001$ ).

The physiological aging process alone leads to a decrease in muscle strength, which can be accelerated 
when associated with comorbidities, which are frequent in this specific population [29]. In the present study, $89.1 \%$ of the sample reported the presence of comorbidities. Functional mobility and HGS showed a moderate negative linear correlation in both sexes. Similar results are found in the literature $[7,17,18,32]$.

Lino et al. [32] identified a drop of $0.08 \mathrm{kgf}$ for each additional second in TUG in a sample of 180 communitydwelling elderly of low socioeconomic status. Kasbia et al. [18] found a worse performance in TUG $(15 \pm 8$ versus $10 \pm 3$ seconds; $p=0.002)$ and low HGS ( $p=$ 0.13 ) in 82 community-dwelling elderly people with dependence in performing IADL when compared to independent elderly people, which is in line with the findings of the present study.

Functional capacity represents the guiding concept of public health policies in force for the elderly population, with importance for analysis both at the collective and individual level [20]. In addition to reflecting the individual's ability to perform activities of daily living, it is also related to important outcomes, such as disease prognosis and mortality [6, 18, 33-35]. Studies suggest that the risk factors associated with decline in functional capacity are female gender, advanced age, low socioeconomic status, high nutritional risk, taking two or more medications for continuous use, fear of falling and low functional mobility [6, 18, 33-35]. Although the nature of the present study did not allow us to establish a causal relationship between the variables analyzed, it is known that functional mobility represents an important component of functional capacity [14], which reinforces the importance of screening elderly people with limited functional mobility in intervention programs.

A weak positive linear correlation was found between functional mobility and number of falls in the present study. It is common for elderly people with functional mobility limitations, which may be due to a fall or not, to be afraid of falling, which can play a protective role against the occurrence of falls, as low self-efficacy in avoiding such events would limit the elderly in high-risk situations [16, 20,27]. Additionally, the predominance of females in the sample $(61.7 \%)$ corroborates this hypothesis, since $72 \%$ of individuals with fear of falling were women.

TUG performance was also considered to be a predictor of fear of falling [27]. Moreira et al. [27] found that for each additional second in TUG there was a 1.36fold increase in fear of falling (odds ratio $=1.36,95 \% \mathrm{CI}$ = 1.07-1.73) in 99 community-dwelling elderly. Utida et al. [16] carried out a cross-sectional study with 201 community elderly assisted in nine Family Health Units in Campo Grande (MS), in which they investigated the fear of falling and its association with functional mobility and number of falls. A positive linear correlation was found between fear of falling and functional mobility ( $p$ $<0.001$ ) and number of falls ( $\mathrm{p}=0.005)$.

The present study found a moderate positive linear correlation between functional mobility and fear of falling in females and weak in males. This difference in behavior between the sexes was already expected, since it corroborates the findings of the literature $[16,20,27]$. The influence of sociocultural factors on the behavior patterns of men and women is widely discussed in the literature, and its importance lies mainly in the adoption of different intervention approaches. Male individuals generally report greater self-efficacy to prevent falls when compared to females, which often does not correspond to their real functional condition. In contrast, female individuals have a greater tendency to restrict activities due to low self-efficacy in preventing falls $[16,20,27]$. An important observation in the present study, which reinforces this finding, was the statistically significant correlation between functional mobility and number of falls in men compared to women.

The broad age range of the sample can be pointed out as a limitation, but the analysis carried out in the subgroup of long-lived elderly allowed the analysis of the behavior of the relationships between the variables in this stratum. The study design can also be pointed out as a limitation because it did not allow us to establish a causal relationship between the variables investigated; however, the methodological quality of the study and the sample size provided a robust data analysis.

\section{Conclusion}

Functional mobility showed a moderate correlation with HGS and functional capacity for instrumental activities of daily living in both sexes and with fear of falling in females. It displayed a weak correlation with fear of falling in males and the number of falls in both sexes. The protective role of fear of falling in individuals with limited functional mobility was identified as a possible explanation for this finding. In addition, the weak correlation between functional mobility and fear of falling in males consists in the fact that men can show overestimated self-efficacy in avoiding falls. The findings and reflections presented can contribute to clinical 
practice aimed at promoting active and healthy aging and, consequently, improving the quality of life of this population. Longitudinal well-designed studies with larger sample sizes are needed to confirm these findings.

\section{Acknowledgement}

The authors would like to thank the support of the National Council of the Scientific Researches (CNPq) - 480163/2012-0 and 301101/2016-7, and National Council for the Improvement of Higher Education (CAPES) - 001 .

\section{References}

1. Agmon M, Lavie L, Doumas M. The association between hearing loss, postural control, and mobility in older adults: a systematic review. J Am Acad Audiol. 2017;28(6):575-88.

2. Beaudart $\mathrm{C}$, Biver $\mathrm{E}$, Bruyère $\mathrm{O}$, Cooper $\mathrm{C}$, Al-Daghri $\mathrm{N}$, Reginster JY, et al. Quality of life assessment in musculoskeletal health. Aging Clin Exp Res. 2018;30(5):413-8.

3. Bergland A, Jorgensen L, Emaus N, Strand BH. Mobility as a predictor of all-cause mortality in older men and women: 1.8 year follow-up in the Tromsø study. BMC Health Serv Res. 2017;17:22.

4. Mahmoudi R, Novella JL, Manckoundia P, Ahssaini F, Lang PO, Blanchard F, et al. Is functional mobility an independent mortality risk factor in subjects with dementia? Maturitas. 2017;103:65-70.

5. Moreira NB, Rodacki ALF, Pereira G. Does functional capacity, fall risk awareness and physical activity level predict falls in older adults in different age groups? Arch Gerontol Geriatr. 2018;77:57-63.

6. Lin SI, Lee HC, Chang KC, Yang YC, Tsauo JY. Functional mobility and its contributing factors for older adults in different cities in Taiwan. J Formos Med Assoc. 2017;116(2):72-9.

7. Brito TA, Coqueiro RS, Fernandes MH, Jesus CS. Determinants of falls in community-dwelling elderly: hierarchical analysis. Public Health Nurs. 2014;31(4):290-7.
8. Homem TS, Guimarães FS, Soares MS, Kasuki L, Gadelha MR, Lopes AJ. Balance control and peripheral muscle function in aging: a comparison between individuals with acromegaly and healthy subjects. J Aging Phys Act. 2017;25(2):218-27.

9. Sgrò F, Licari D, Coppola R, Lipoma M. Assessment of balance abilities in elderly people by means of a clinical test and a low-cost force plate. Kinesiology. 2015;47(1): 33-43.

10. Barry E, Galvin R, Keogh C, Horgan F, Fahey T. Is the Timed Up and Go test a useful predictor of risk of falls in community dwelling older adults: a systematic review and meta-analysis. BMC Geriatr. 2014;14:14.

11. Dubois A, Bihl T, Bresciani JP. Automatic measurement of fall risk indicators in timed up and go test. Inform Health Social Care. 2019;44(3):237-45.

12. Lusardi MM, Fritz S, Middleton A, Allison L, Wingood M, Phillips E, et al. Determining risk of falls in community dwelling older adults: a systematic review and metaanalysis using posttest probability. J Geriatr Phys Ther. 2017;40(1):1-36.

13. Park SH. Tools for assessing fall risk in the elderly: a systematic review and meta-analysis. Aging Clin Exp Res. 2018;30(1):1-16.

14. Podsiadlo D, Richardson S. The timed "Up \& Go": a test of basic functional mobility for frail elderly persons. J Am Geriatr Soc. 1991;39(2):142-8.

15. Hofheinz M, Mibs MPH. The Prognostic Validity of the Timed Up and Go test with a dual task for predicting the risk of falls in the elderly. Gerontol Geriatr Med. 2016;2: $1-5$.

16. Utida KAM, Budib MB, Batiston AP. Fear of falling associated with sociodemographic and lifestyle variables and clinical conditions in elderly people registered with the Family Health Strategy in Campo Grande, Mato Grosso do Sul. Rev Bras Geriatr Gerontol. 2016;19(3):441-52.

17. Cardon-Verbecq C, Loustau M, Guitard E, Bonduelle M, Delahaye E, Koskas P. Predicting falls with the cognitive timed up-and-go dual task in frail older patients. Ann Phys Rehabil Med. 2017;60(2):83-6.

18. Kasbia GS, Farragher J, Kim SJ, Famure O, Jassal SV. A cross-sectional study examining the functional independence of elderly individuals with a functioning kidney transplant. Transplantation. 2014; 98(8):864-70. 
19. Malta M, Cardoso LO, Bastos FI, Magnanini MMF, Silva CMFP. STROBE initiative: guidelines on reporting observational studies. Rev Saude Publica. 2010;44(3):559-65.

20. Cruz DT, Vieira MT, Bastos RR, Leite ICG. Fatores associados à fragilidade em uma população de idosos da comunidade. Rev Saude Publica. 2017;51:106.

21. Brasil, Ministério da Saúde, Secretaria de Atenção à Saúde, Departamento de Atenção Básica. Envelhecimento e saúde da pessoa idosa. Brasília, DF: Ministério da Saúde; 2006.

22. Rahman MM, Davis DN. Addressing the class imbalance problem in medical datasets. IJMLC. 2013;3(2):224-8.

23. Rolfson DB, Majumdar SR, Tsuyuki RT, Tahir A, Rockwood K. Validity and reliability of the Edmonton Frail Scale. Age Aging. 2006;35(5):526-9.

24. Fess EE. Grip strength. In: Casanova JS, editor. Clinical assessment recommendations. 2nd ed. Chicago: American Society of Hand Therapists; 1992. p. 41-5.

25. Lawton MP, Brody EM. Assessment of older people: selfmaintaining and instrumental activities of daily living. Gerontologist. 1969;9(3):179-86.

26. Camargos FF, Dias RC, Dias JMD, Freire TF. Adaptação transcultural e avaliação das propriedades psicométricas da Falls Efficacy Scale - International em idosos brasileiros (FES-I-BRASIL). Rev Bras Fisioter. 2010;14(3):237-43.

27. Moreira BS, Anjos DM, Pereira DS, Sampaio RF, Pereira LS, Dias RC, et al. The geriatric depression scale and the timed up and go test predict fear of falling in communitydwelling elderly women with type 2 diabetes mellitus: a cross-sectional study. BMC Geriatr 2016;3(16):56.
28. Hazra A, Gogtay N. Biostatistics series module 6: correlation and linear regression. Indian J Dermatol. 2016;61(6):593-601.

29. Celis-Morales CA, Petermann F, Hui L, Lyall DM, Iliodromiti S, McLaren J. Associations Between Diabetes and Both Cardiovascular Disease and All-Cause Mortality Are Modified by Grip Strength: Evidence From UK Biobank, a Prospective Population-Based Cohort Study. Diabetes Care. 2017;40(12):1710-8.

30. Dodds RM, Syddall HE, Cooper R, Kuh D, Cooper C, Sayer AA. Global variation in grip strength: a systematic review and meta-analysis of normative data. Age Ageing. 2016;45(2):209-16.

31. Granic A, Davies K, Jagger C, Dodds RM, Kirkwood TBL, Sayer AA. Initial level and rate of change in grip strength predict all-cause mortality in very old adults. Age Ageing. 2017;46(6):970-6.

32. Lino VT, Rodrigues NC, O'Dwyer G, Andrade MK, Mattos IE, Portela MC. Handgrip strength and factors associated in poor elderly assisted at a primary care unit in Rio de Janeiro, Brazil. PLoS One. 2016;11(11):e0166373.

33. Alexandre TS, Corona LP, Nunes DP, Santos JLF, Duarte YAO, Lebrão ML. Disability in instrumental activities of daily living among older adults: gender differences. Rev Saude Publica. 2014;48(3):379-89.

34. Matos FS, Jesus CS, Carneiro JAO, Coqueiro RDS, Fernandes MH, Brito TA. Reduced functional capacity of community-dwelling elderly: a longitudinal study. Cien Saude Colet. 2018;23(10):3393-401.

35. Sugiura Y, Tanimoto Y, Imbe A, Inaba Y, Sakai S, Shishikura K. Association between functional capacity decline and nutritional status based on the nutrition screening initiative checklist: a 2-year cohort study of Japanese community-dwelling elderly. PLoS One. 2016;11(11):e0166037.
Received: 05/22/2019

Recebido: 22/05/2019

Approved: 02/03/2020

Aprovado: 03/02/2020 